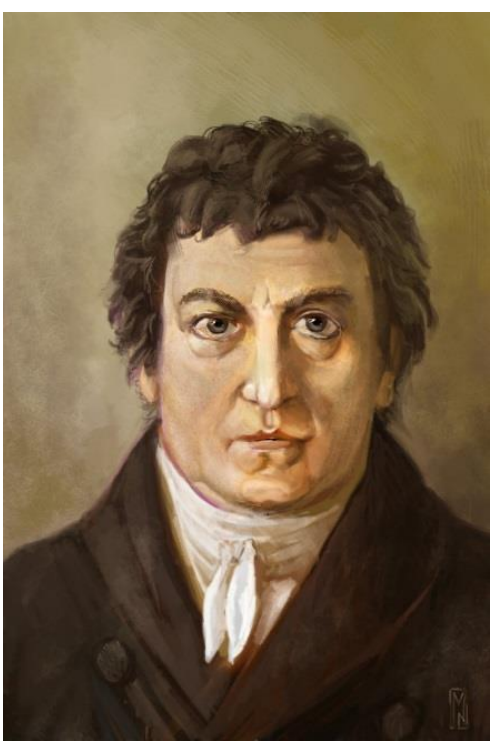

Johann Gottlieb Fichte

\section{A Filosofia da História e da Cultura em Fichte}

\author{
IV Jornadas \\ Rede Ibérica de Estudos Fichteanos - Red \\ Ibérica de Estudios Fichteanos - Xarxa Ibérica \\ d'Estudis Fichtians \\ Faculdade de Letras da Universidade de Coimbra \\ Departamento de Filosofia, Comunicação e \\ Informação \\ Centro de Estudos Clássicos e Humanísticos - CECH
} 26, 27 e 28 de Outubro de 2016

\title{
Chamada de Comunicações
}

Terá lugar em Coimbra, Portugal, nos dias 26, 27 e 28 de Outubro de 2016, as IV Jornadas da Rede Ibérica de Estudos Fichteanos - RIEF com o tema A Filosofia da História e da Cultura em Fichte.

Toda a obra de Fichte poderá ser objecto de estudo a propósito do tema geral, estando prevista uma especial atenção às obras do período central do filósofo, nomeadamente Die Grundzüge der gegenwärtigen Zeitalter, Reden an die Deutsche Nation e Anweisung zum seligen Leben, além de duas obras tardias, a Rechtslehre 1812 e Die Staatslehre 1813.

As línguas de trabalho são as ibéricas.

Os interessados em participar com uma comunicação devem enviar um título, resumo e uma breve nota curricular para o endereço jornadasrief2016@gmail.com até 30 de Junho de 2016.

Conferencistas previstos:

Ana Carrasco Conde, Carlos Morujão, Faustino Oncina Coves, Diogo Ferrer, Felipe Schwember Augier, Héctor Arrese Igor, Jacinto Rivera, João Gerald Martins da Cunha, Luciano Corsico, Luciano Utteich, Manuel Jiménez Redondo, Marco Rampazzo Bazzan, Mariano Gaudio, Oscar Cubo, Salvi Turró, Valerio Rocco 